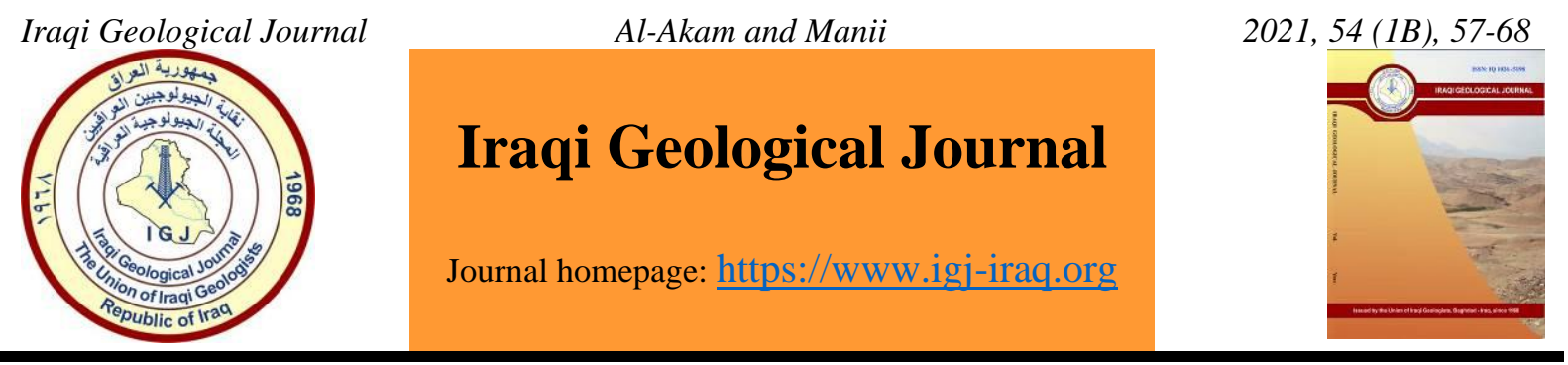

\title{
Measurement of Some Climatic Parameter in Babylon Governorate by Statistical and Mathematical Methods
}

\author{
Mahmood A. Al-Akam ${ }^{1, *}$ and Jwad K. Manii ${ }^{2}$ \\ ${ }^{1}$ Department of Geology, College of Science, University of Babylon, Babil, Iraq \\ ${ }^{2}$ Department of Geology, College of Science, University of Babylon, Babil, Iraq \\ *Correspondence: Mahmood.ak93@gmail.com \\ Received: 22 October 2020; Accepted: 15 December 2020; Published: 28 February 2021
}

\begin{abstract}
Evaporation transpiration is one of the most important results in the water balance equation for any natural area or water body, and it is also a critical component of the hydrological cycle. The relationship between temperature and transpiration was obtained using the Thornthwaite method in three stations along with Babylon Governorate. The data for the three meteorological stations were taken for 10 years. The value of climate change was obtained within the study area, including temperature, evaporation, humidity, and rainfall. The value of potential evapotranspiration was calculated by the Thornthwaite method, and the highest value was obtained in July (421.9), and the lowest value in January (3.66). Also, the increase in water was calculated for a study area. It appeared that the increase in evapotranspiration and decrease was in direct relationship with the temperature intensity of the study area.
\end{abstract}

Keywords: Evaporation transpiration; Rainfall; Thornthwaite method; January; Relationship

\section{Introduction}

The climate is considered one of the most important components of the natural environment and it has a great impact on the rest of the other components, such as vegetation, geomorphological features, and soil. It is also a reason for the local changes that occur within the local environment due to its association with the life activities of living organisms (Shaker, 1985). The methods usually used in measuring climate elements such as solar radiation, temperature, atmospheric pressure, etc. are using devices prepared in climate stations as well as radars, satellites, and satellites prepared for this purpose. The occurrence of an error rate in measuring devices and the different types among the countries of the world has prompted some to lay down rules for calculating some climatic phenomena to obtain the greatest accuracy (Manii, 2003). The importance of studying climatic conditions is one of the important foundations that compose the full picture of the prevailing nature in the place. The climate of the region (Babylon Governorate) is dry continental as it is the climate of the middle section of Mesopotamia, where it is characterized by a very different temperature. The temperature is very high during the day in the summer and the night temperature is very low during the winter. Al-Lhaebi et al. (2020) studies the climatic conditions, northern Iraq and mentioned that the climate is warm and arid. The study aims to evaluate the climate in Babylon by using some statistical measurements.

DOI: $10.46717 /$ igj.54.1B.5Ms-2021-02-23 


\section{Materials and Methods}

The materials used in this research were:

- Annual and monthly temperature records for three stations along the Babylon.

- Thornthwaite formula.

- Grapher and Excel programs demonstrating graphs and contour maps Methods which are used in this paper include:

- The annual and monthly air temperatures of three stations were used to calculate the potential evapotranspiration (PE) using the Thornthwaite method.

- The data obtained were recorded in tables, including temperature, humidity, evaporation, and precipitation, and the evapotranspiration was calculated as well as the rain precipitation was used to find the water increase and decrease for the area. Tables 1,2 and 3 showed the values of the data obtained.

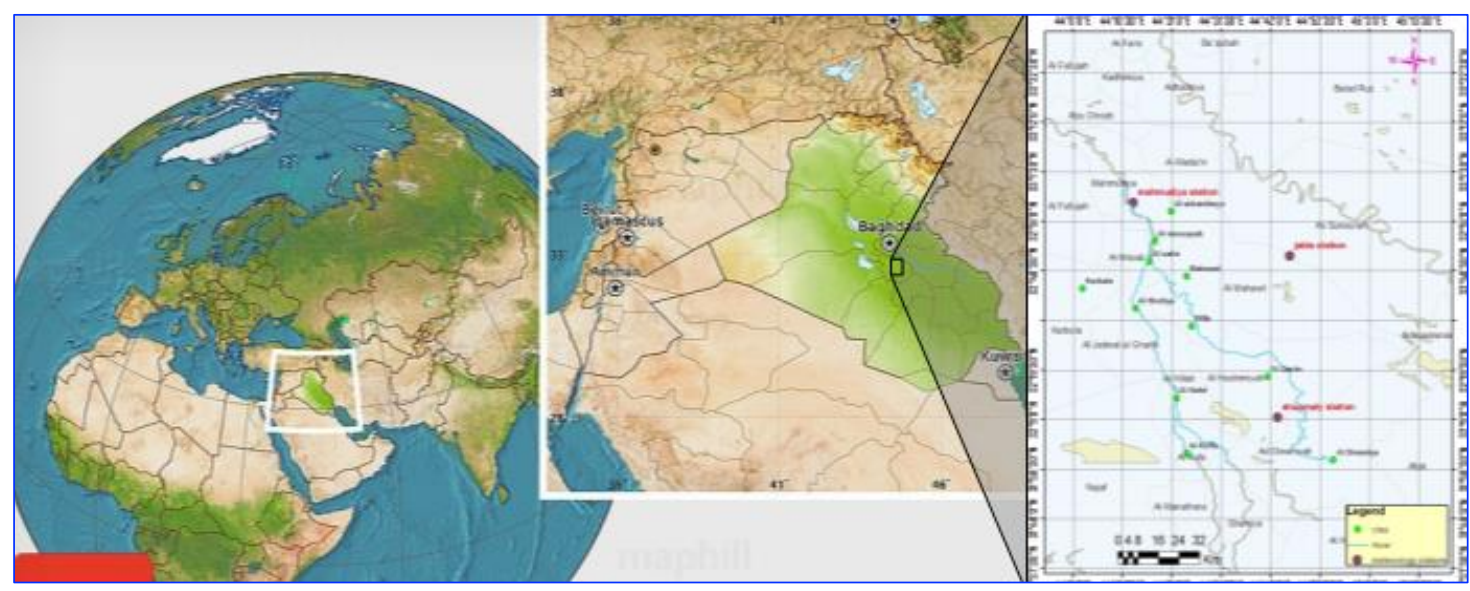

Fig. 1. Distribution map of meteorological stations in the study area

Table 1. Climate parameter rates recorded site (2010-2020) for the Mahmoudiyah station

\begin{tabular}{lccc}
\hline Months & Temperature & Rainfall & Relative humidity \\
\hline Jan. & 10.722 & 16.67 & 63.7 \\
Feb. & 13.12 & 11.09 & 57.78 \\
Mar. & 18.67 & 17.89 & 48.34 \\
Apr. & 25.62 & 7.14 & 38.57 \\
May. & 32.95 & 4.58 & 30.33 \\
Jun. & 38.9 & 0.01 & 20.05 \\
Jul. & 41.78 & 0.083 & 18.26 \\
Aug. & 41.59 & 0.034 & 18.88 \\
Sep. & 36.87 & 0.001 & 21.23 \\
Oct. & 29.39 & 6.952 & 32.04 \\
Nov. & 19.055 & 16.63 & 49.76 \\
Dec. & 12.48 & 19.53 & 61.63 \\
\hline
\end{tabular}


Table 2. Climate parameter rates recorded site (2010-2020) for the Jabla station

\begin{tabular}{cccc}
\hline Months & Temperature & Rainfall & Relative humidity \\
\hline Jan. & 10.9 & 19.22 & 60.88 \\
Feb. & 12.9 & 10.73 & 60.48 \\
Mar. & 16.6 & 16.54 & 44.61 \\
Apr. & 23 & 8.74 & 36.47 \\
May. & 29 & 5.99 & 28.01 \\
Jun. & 33.3 & 0.07 & 17.76 \\
Jul. & 34.9 & 0.41 & 16.03 \\
Aug. & 34.5 & 0.22 & 16.72 \\
Sep. & 30.4 & 0.01 & 20.11 \\
Oct. & 24.7 & 6.7 & 29.87 \\
Nov. & 17.7 & 18.65 & 47.92 \\
Dec. & 12.9 & 17.47 & 58.94 \\
\hline
\end{tabular}

Table 3. Climate parameter rates recorded site (2010-2020) for the Shuomley station

\begin{tabular}{cccc}
\hline Months & Temperature & Rainfall & Relative humidity \\
\hline Jan. & 11.82 & 20.05 & 53.64 \\
Feb. & 14.21 & 9.05 & 48.05 \\
Mar. & 20.02 & 13.32 & 38.74 \\
Apr. & 27.06 & 8.9 & 30.73 \\
May. & 34.5 & 7.75 & 23.62 \\
Jun. & 40.34 & 0.26 & 14.71 \\
Jul. & 43.1 & 0.44 & 13.27 \\
Aug. & 42.92 & 0.15 & 13.98 \\
Sep. & 38.32 & 0.001 & 15.64 \\
Oct. & 30.78 & 5.43 & 25.55 \\
Nov. & 20.16 & 19.14 & 44.7 \\
Dec. & 13.56 & 14.56 & 53.46 \\
\hline
\end{tabular}

\section{Results and Discussion}

\subsection{Rainfall}

Three stations were chosen from north to south in the study area (Mahmudiyah, Jibla, and Shomily). The Mahmudiyh station recorded monthly rates of rainfall ranging from 0.01-19.53 mm (Fig. 2). months where the rains are limited between October and May. Its peak in December reached more than $19.53 \mathrm{~mm}$. The dry period starts from June to September. The Jabla station recorded monthly rates of rainfall ranging (0.01-19.22) mm months (Fig. 3) where the rains are limited between October and May. Its peak in January reached more than $19.22 \mathrm{~mm}$. The dry period starts from June to September. The shomily station recorded monthly rates of rainfall ranging (0.001-20.05) mm months (Fig. 4) where the rains are limited between October and May. Its peak in January reached more than $20.05 \mathrm{~mm}$. The dry period starts from June to September. Except for some rainy years, where relatively few local rains fall in these months that the increase of rainfalls affects the groundwater and soil through the increase of organic matter as a result of plant growth as well as the processes of chelating and transfer of materials from the upper parts to the lower parts (Al-Tawel, 1983). 


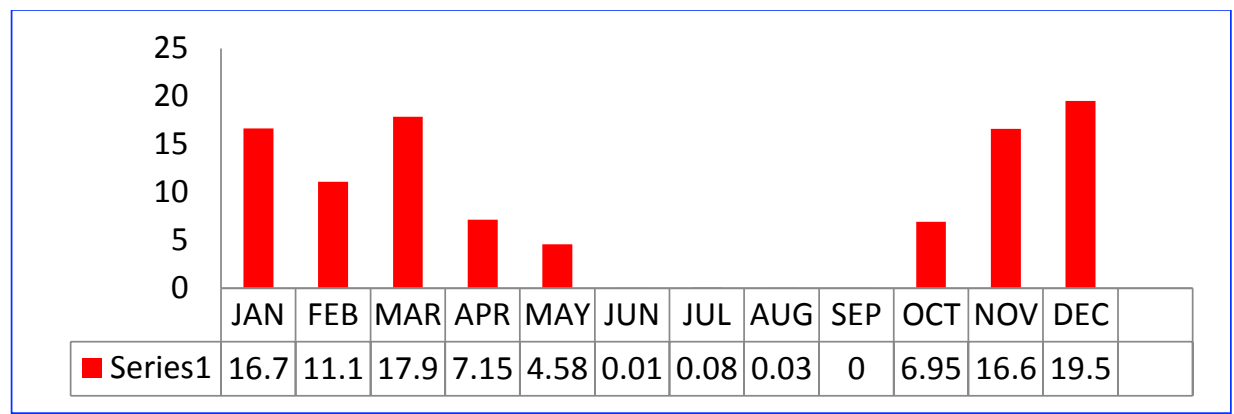

Fig. 2. The annual average of rainfall for ten years for the Mahmoudiya station

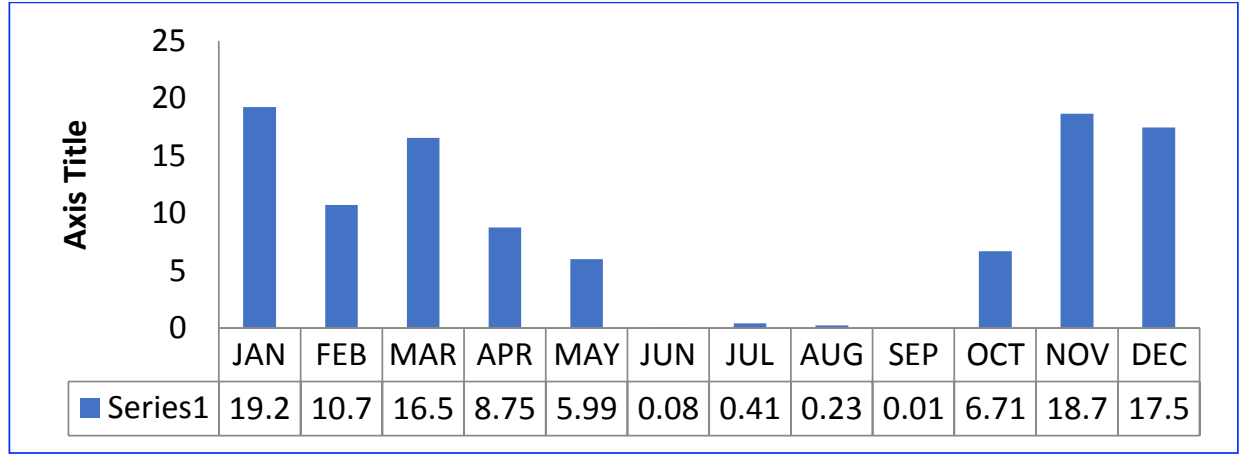

Fig. 3. The annual average of rainfall for ten years for the jabla station

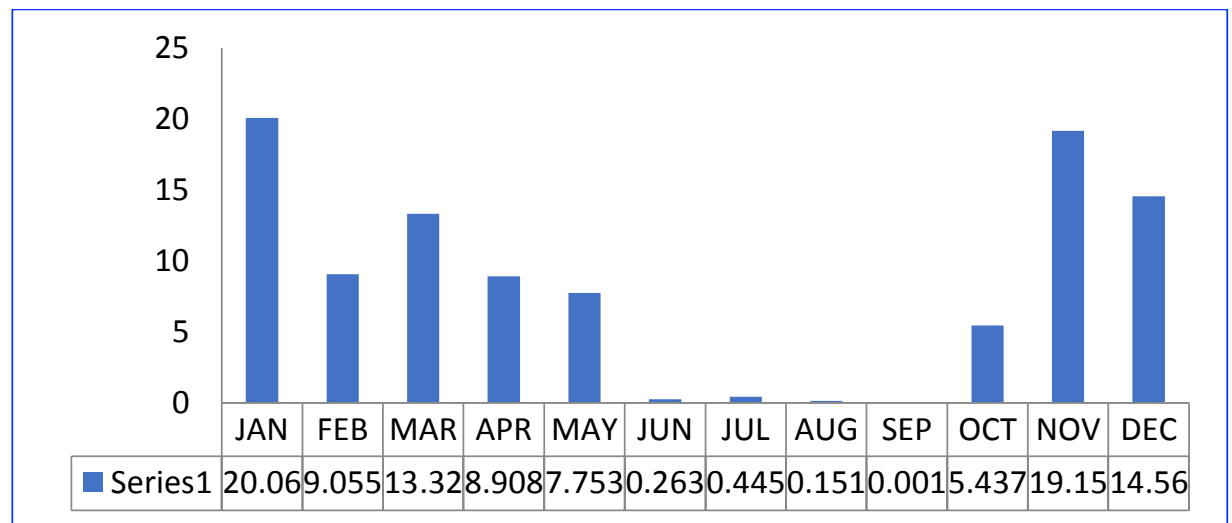

Fig. 4. The annual average rainfall for ten years for the Shomily station

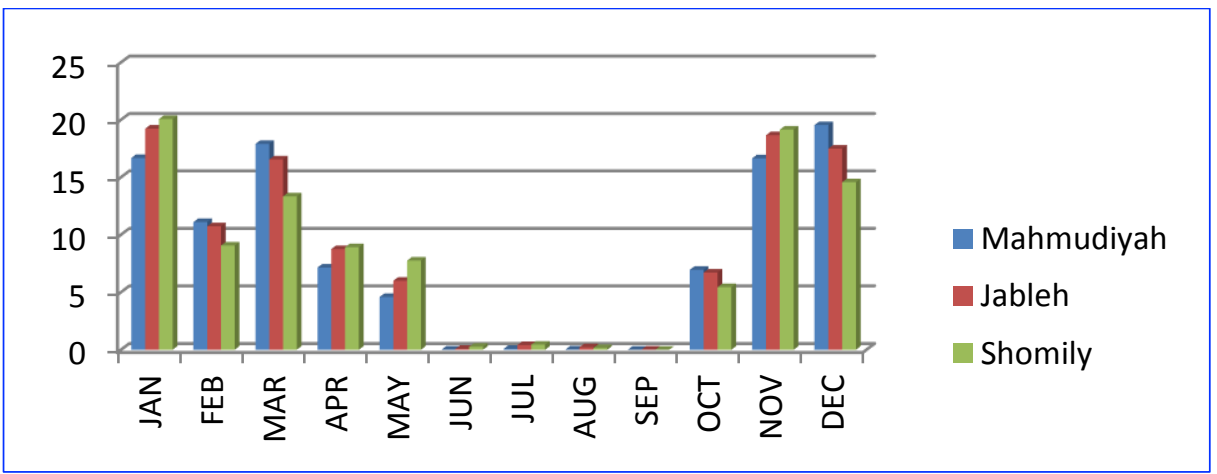

Fig. 5. Comparisons of rainfall between three stations taken 


\subsection{Temperature}

The temperature reaches the highest value in July, August, and it reaches the lowest level in the month of winter, where it sometimes reaches below the seminal zero in some winter nights. The monthly rates of temperature for the years (2010-2020) for July (41.78) and (10.72) for January for the same period according to the climatic information recorded from (2010-2020) for the Mahmudiya station.

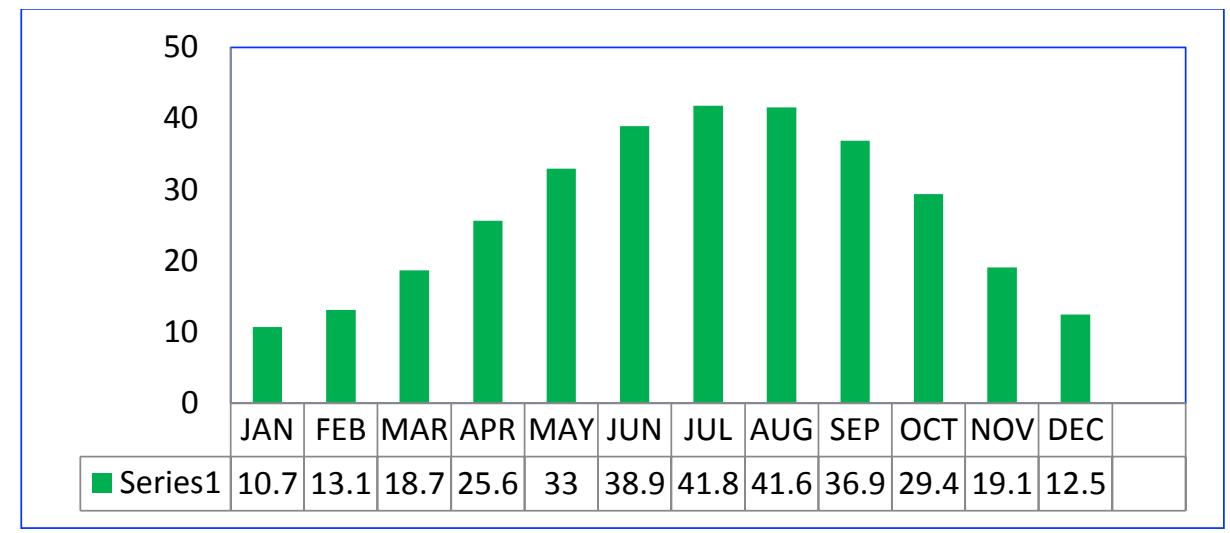

Fig. 6. The annual average temperature for ten years for the Mahmoudiya station

In the Jibla station, the temperature reaches the highest value in July and August, and it reaches its lowest level in the month of winter, where it sometimes reaches below the percentile zero in some winter nights. The monthly rates of temperature for the years (2010-2020) for the month of July (42.49) and (11.31) for January for the same period according to the climatic information recorded from the NASA climate site (2010-2020).

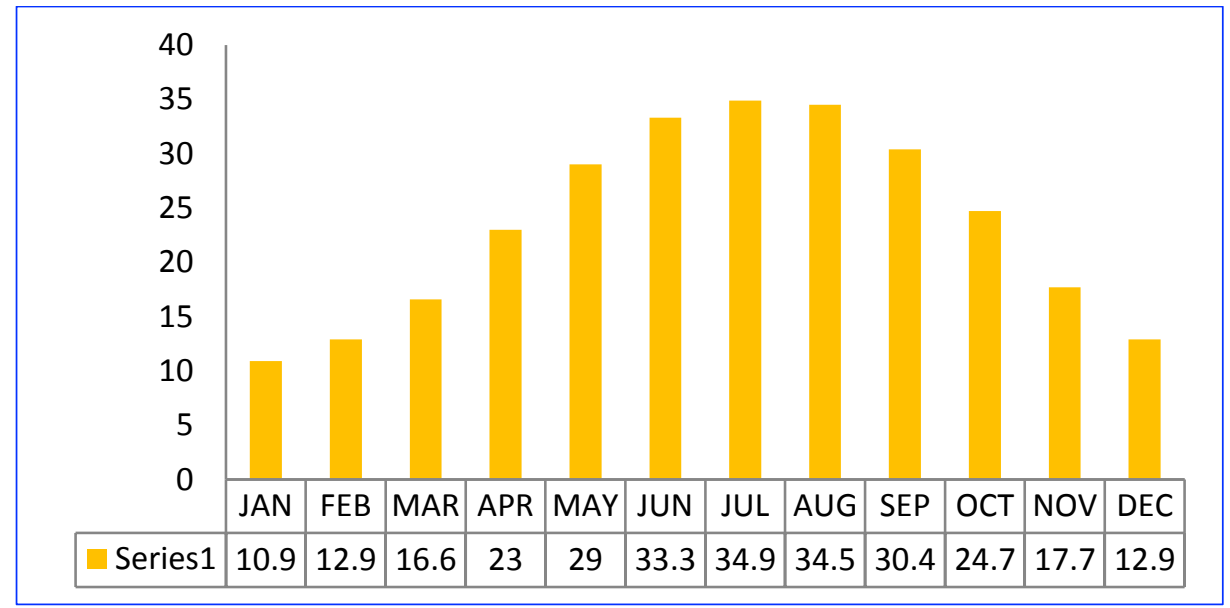

Fig. 7. The annual average temperature for ten years for the Jabla station

In the Shomily station, the temperature reaches to highest value in July, August, and it reaches its lowest level in the month of winter, where it sometimes reaches below the percentile zero in some winter nights. The monthly rates of temperature for the years (2010-2020) for the month of Show in July (43.11) and (11.82) for January for the same period according to the climatic information recorded from the (2010-2020). 


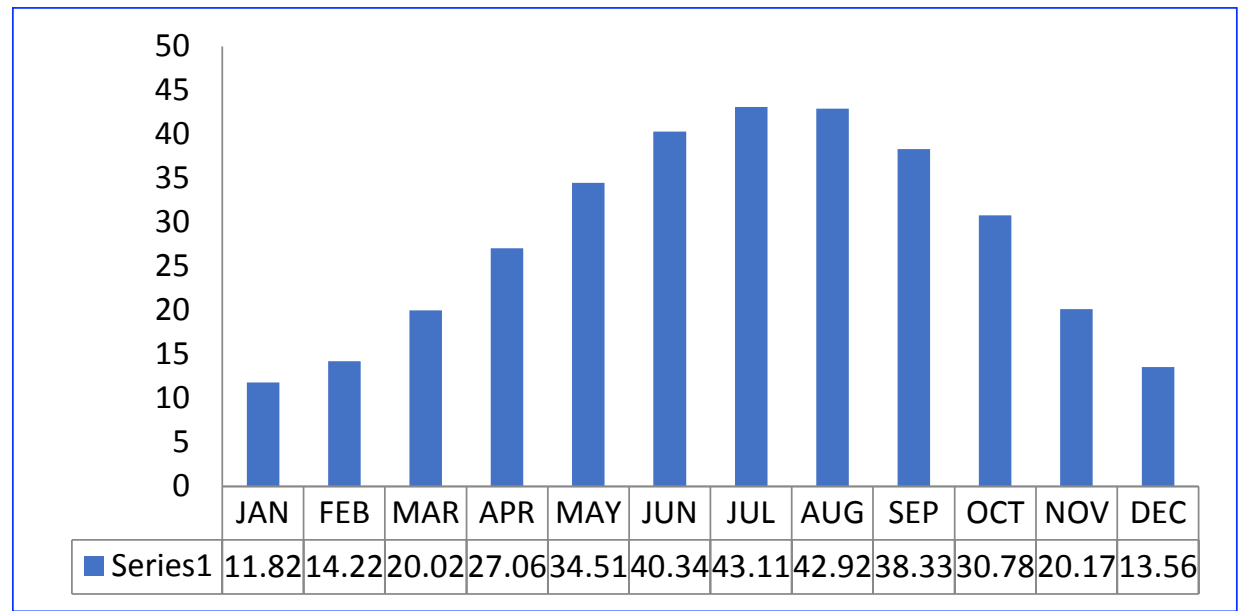

Fig. 8. The annual average of ten years for the AL-shomily station

It was found that the direction of temperature increase is different with the trend of increasing precipitation and relative humidity (Fig.8) and showed the increase in temperature affects chemical reactions, physical changes and the analysis of organic matters approved in Hove's law (Vant Hoffs low), where each temperature increase 10 In temperature, the speed of chemical reactions increases at a rate of 2-3 once (Al-Tawel, 1983).

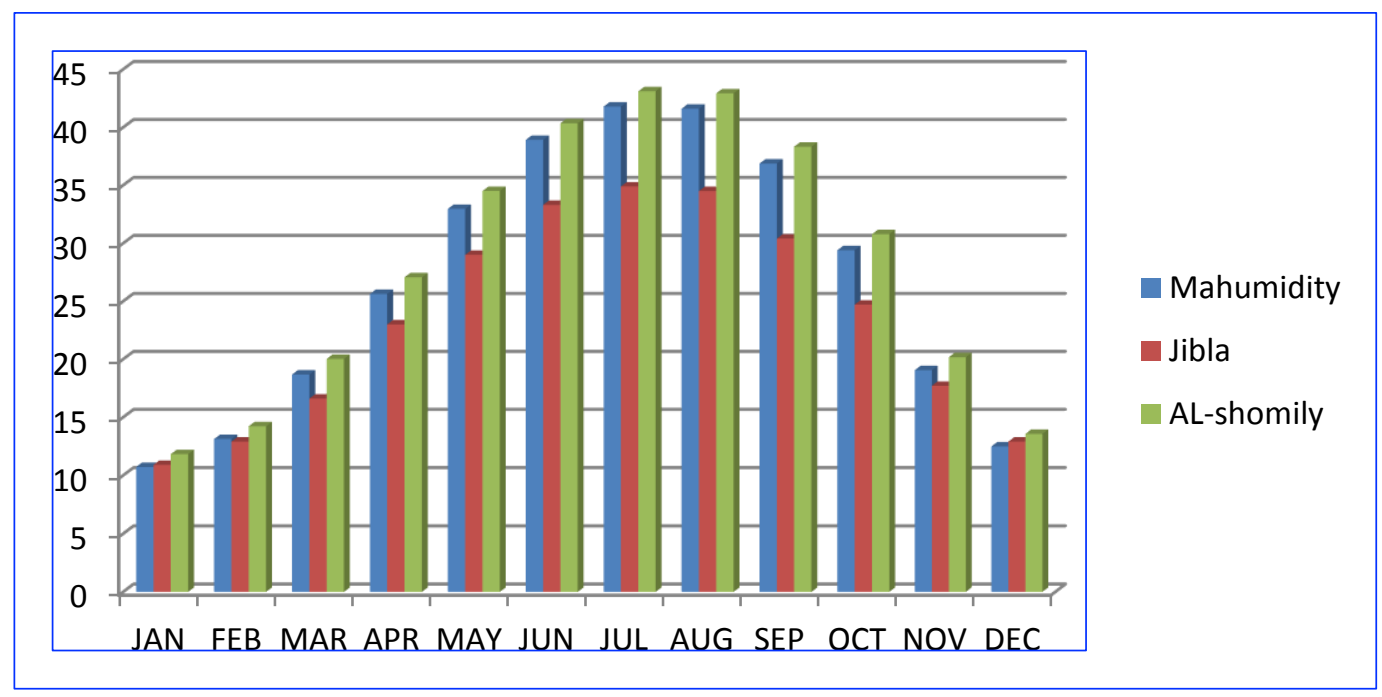

Fig. 9. Comparisons between three stations

\subsection{Relative Humidity}

The relative humidity is a term used to estimate the mass of water vapor present in a given mass of gaseous mixture or air about the mass of water vapor required to saturate the same air mass and at the same temperature. (Hussain et al., 2000), and it can be defined as a measure of the air capacity to absorb water vapor and is measured by passing air on two thermometers, one of which is a Wet Bulb Thermometer and the other one is a Dry Bulb Thermometer. And this device is called psy chrometer. Relative humidity has an inverse relationship with both evaporation and temperature, and a direct relationship with rainfall (Manii, 2003). The humidity reached the period from 2010-2020 in Mahmudya, for July $18.26 \%$ and for January, $63.70 \%$. A decrease in relative humidity during the summer due to increase in temperature and the absence of rain, while the relative humidity increases in the winter due to the intensity of the rainfall and the decrease in temperature (Fig. 9). 


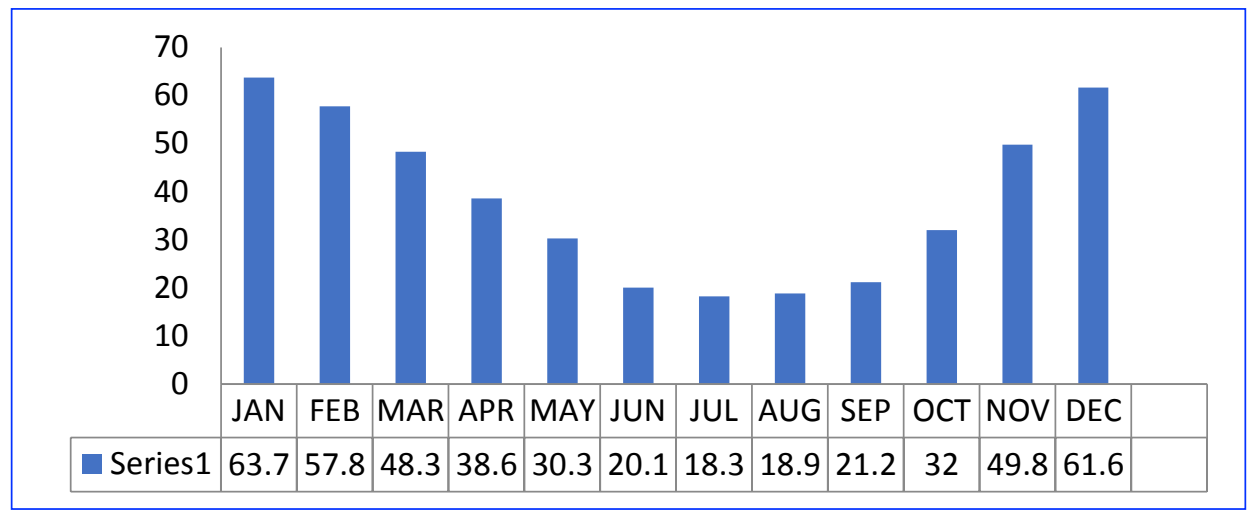

Fig. 10. The annual average relative Humidity for ten years for the Mahmoudiya station

The humidity reached the period from 2010-2020 in Jibla. for July 16.03\% and for January, $60.89 \%$. A decrease in relative humidity during the summer month due to the increase in temperature and the absence of rain, while the relative humidity increases in the winter month due to the intensity of the rainfall and the decrease in temperature (Fig. 10).

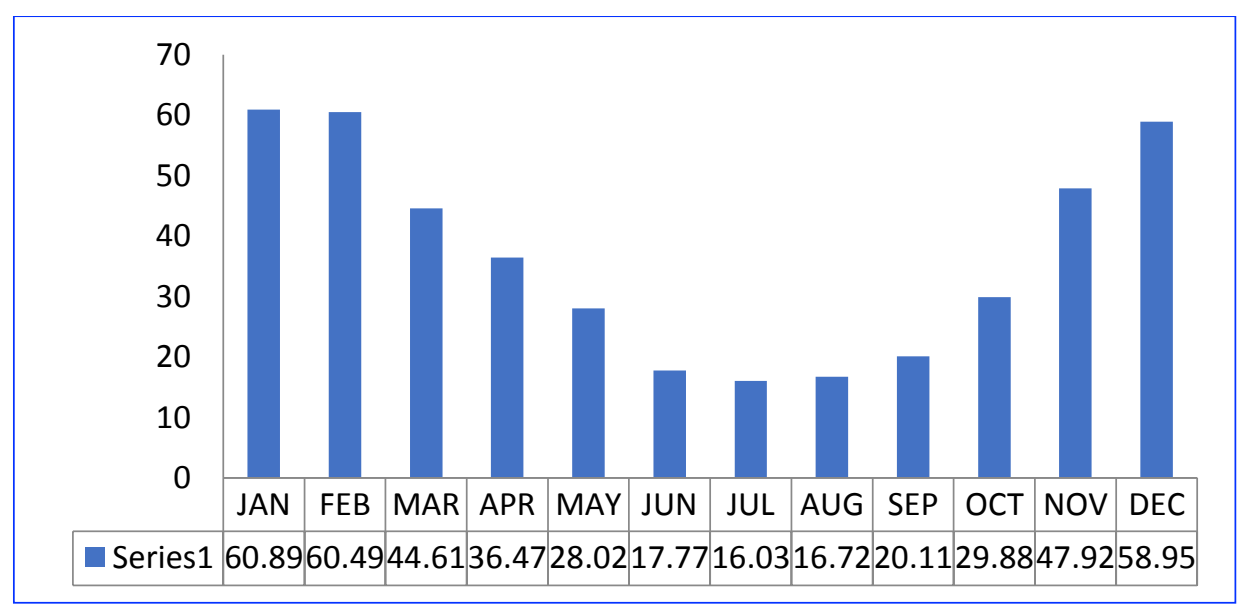

Fig. 11. The annual average relative Humidity for ten years for the Jabla station

The humidity reached the period from 2010-2020 in Al-shomily. for July $13.27 \%$ and for January,53.64\%. A decrease in relative humidity during the summer month due to the increase in temperature and the absence of rain, while the relative humidity increases in the winter month due to the intensity of the rainfall and the decrease in temperature (Fig. 11).

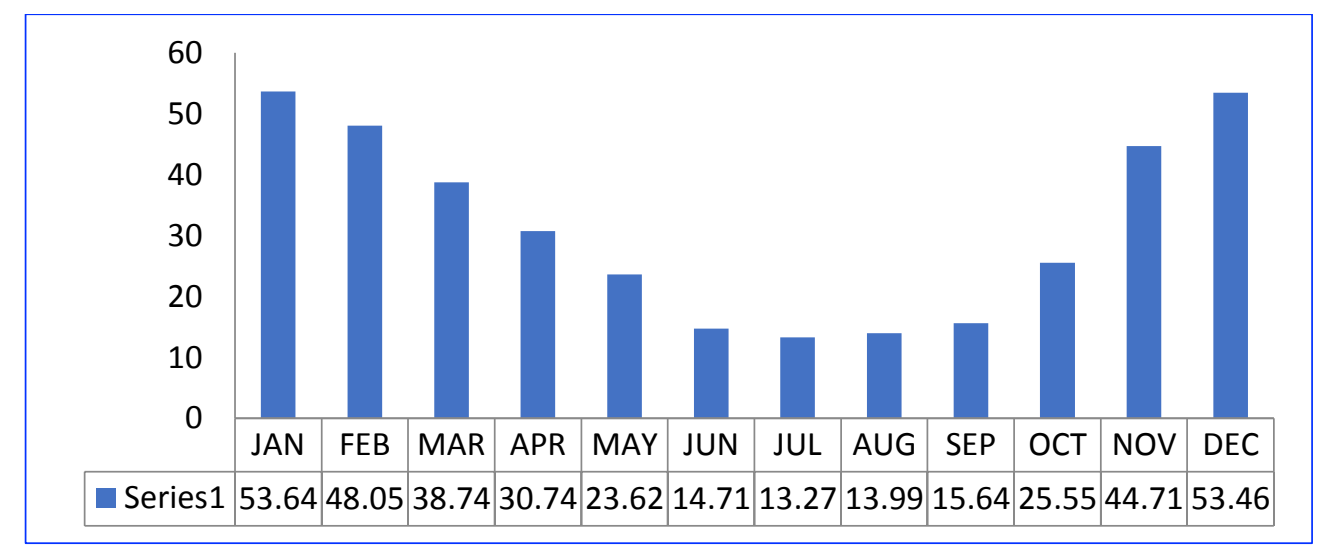

Fig. 12. The annual average of Relative Humidity for ten years for the Al-shomily station 


\subsection{Evaporation}

The process of transformation water from the liquid state to the gaseous state by escaping the water molecules containing the kinetic energy inherent in the water. As the temperature increases, the number of fleeing molecules increases, the kinetic energy of the water increases, and the surface tensile strength decreases (Hussain et al. 2000). Evaporation is affected by many factors such as solar radiation and air temperature, the evaporation surface and the decrease in saturation of air, wind speed, and air pressure, groundwater evaporation leads to the deposition of gypsum minerals, calcite and chloride salts, and therefore when water penetrates it leads to water fortification with these elements (Mazor, 1990).The evaporation in Jabla station in December is $2.05 \mathrm{~mm}$ and $9.82 \mathrm{~mm}$ July (Fig.12).

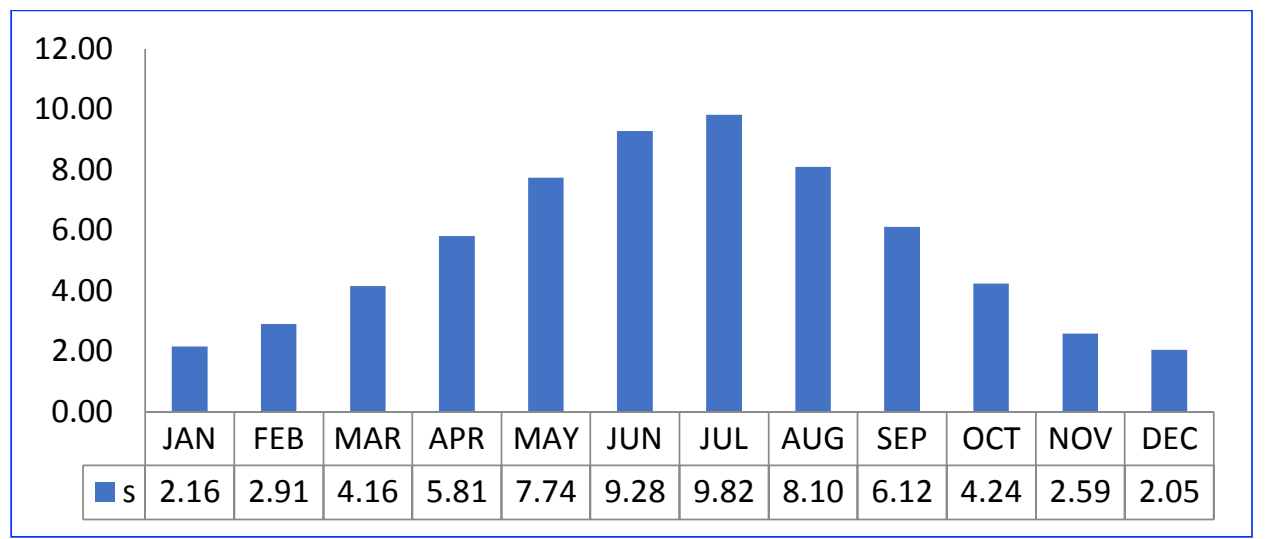

Fig. 13. The annual average of evaporation for ten years for the jabla Station solar brightness

which represents the number of possible sunrise hours between sunrise and sunset and reached to 12 hours during years of 2009 to 2019 in June, July, the lowest rate is 6 hours in January, and the number of hours of solar brightness is related to a direct relationship with both evaporation and temperature.

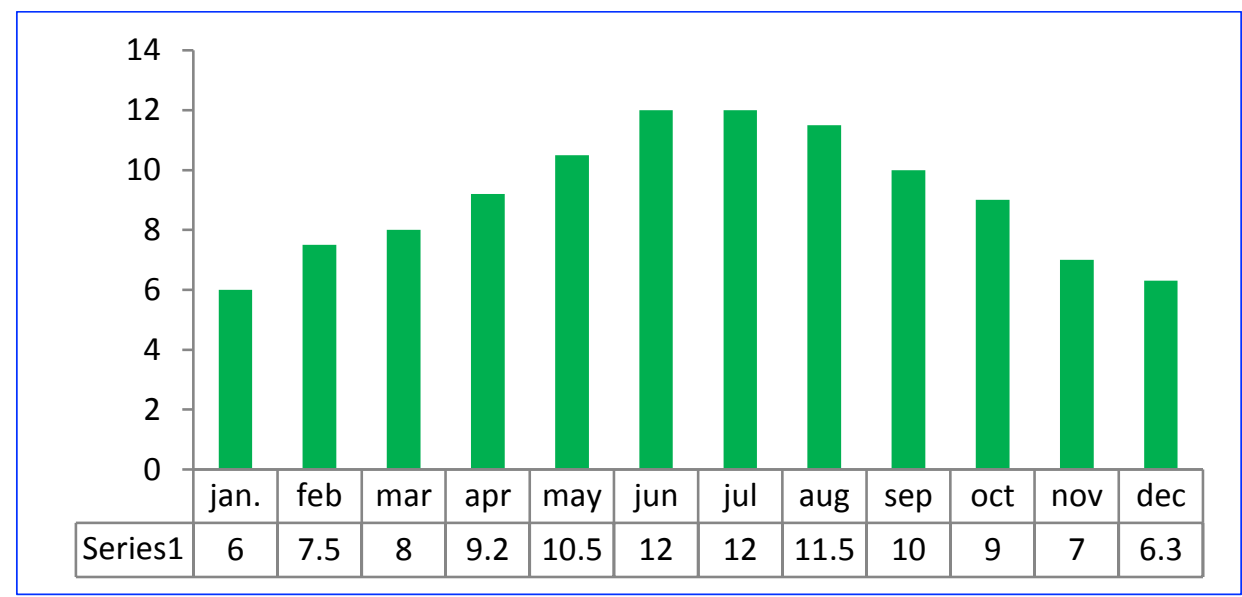

Fig. 14. The annual average of solar brightness for ten years for the Jabla station

\subsection{Evapotranspiration}

The process of evaporation resulting from the two states, the first process originating from the plant by the process of transpiration and the second source is the soil and the total amount of evaporation resulting from the process of transpiration in plants and evaporation from the surface of the earth is called Potential Evapotranspiration (Hussain et al. 2000). Potential evapotranspiration is influenced by plant quality, water loss capacity, and water availability in the soil. Due to the influence of the process of evaporation and transpiration by climate factors, measuring the values of these processes with devices 
is not easy. Therefore, several theories have been developed to calculate the values of evapotranspiration, such as Thornthwate (1948).

To calculate the evapotranspiration in the study area, a method was adopted Thornthwaite (1948), and the reason for choosing this method is the availability of climate variables that enter into this equation, and the following is an explanation of the method:

Evapotranspiration by Thornthwait Method (Thornthuwait) proposed a method for calculating the evapotranspiration latent transpiration using the following equation:

$$
j=\left[t_{n} / 5\right]^{1.514}
$$

$\mathrm{j}=$ Monthly temperature coefficient

$\mathrm{t}_{\mathrm{n}}=$ Monthly rate of heat

And to find the annual temperature coefficient $\mathrm{J}$ which is equal to

$$
J=\sum_{1}^{12} j \text { for the } 12 \text { months }
$$

The latent evapotranspiration for any month is equal to:

$$
P E X=16\left(\frac{10 t}{J}\right)^{a}(\mathrm{~mm} / \text { month })
$$

As the pex evaporation-potential transpiration is the standard

$$
a=\left(6.75 * 10^{-7}\right) J^{3}-\left(7.71 * 10^{-5}\right) J^{2}+\left(1.792 * 10^{-2}\right) J+0.492
$$

And this value (PEX) of latent transpiration evaporation depends on the assumption that the number of days of the month is (30) days and the number of hours of sunrise (12) hours. The corrected value of latent evaporation can be found from the following equation (Wilson, 1970).

$$
P E=P E X \frac{D T}{360}
$$

$\mathrm{PE}=$ Latent transpiration evaporation

$\mathrm{D}=$ The number of days of the month

$\mathrm{T}=$ The number of possible sunrise hours (between sunrise and sunset)

Table 4. Thornthwaite method for the period (2009-2020) calculated evapotranspiration

\begin{tabular}{cccc}
\hline Month & tn & j & PE \\
\hline Jan. & 10.9 & 3.254 & 2.099537 \\
Feb. & 12.9 & 4.199 & 4.610127 \\
Mar & 16.6 & 6.152 & 17.9748 \\
Apr. & 23 & 10.079 & 58.57509 \\
May. & 29 & 14.316 & 164.6972 \\
Jun. & 33.3 & 17.650 & 320.347 \\
Jul. & 34.9 & 18.949 & 421.9548 \\
Aug. & 34.5 & 18.622 & 366.5896 \\
Sep. & 30.4 & 15.376 & 223.3115 \\
Oct. & 24.7 & 11.228 & 95.57813 \\
Nov. & 17.7 & 6.779 & 16.17562 \\
Dec. & 12.9 & 4.199 & 3.638586 \\
& & 130.804 & \\
\hline
\end{tabular}


Table 5. Constant K in Thornthwaite method (Al-Sudani,2019)

\begin{tabular}{ccccccccccccc}
\hline & Jan. & Feb. & Mar. & Apr. & May & June & July & Aug. & Sep. & Oct. & Nov. & Dec. \\
\hline $60^{\circ} \mathrm{N}$ & 0.54 & 0.67 & 0.97 & 1.19 & 1.33 & 1.56 & 1.55 & 1.33 & 1.07 & 0.84 & 0.58 & 0.48 \\
$50^{\circ} \mathrm{N}$ & 0.71 & 0.84 & 0.98 & 1.14 & 1.28 & 1.36 & 1.33 & 1.21 & 1.06 & 0.9 & 0.76 & 0.68 \\
$40^{\circ} \mathrm{N}$ & 0.8 & 0.89 & 0.99 & 1.1 & 1.2 & 1.25 & 1.23 & 1.15 & 1.04 & 0.93 & 0.83 & 0.78 \\
$30^{\circ} \mathrm{N}$ & 0.87 & 0.93 & 1 & 1.7 & 1.14 & 1.17 & 1.16 & 1.11 & 1.03 & 0.96 & 0.89 & 0.85 \\
$20^{\circ} \mathrm{N}$ & 0.92 & 0.96 & 1 & 1.05 & 1.09 & 1.11 & 1.1 & 1.07 & 1.02 & 0.98 & 0.93 & 0.91 \\
$10^{\circ} \mathrm{N}$ & 0.97 & 0.98 & 1 & 1.03 & 1.05 & 1.06 & 1.05 & 1.04 & 1.02 & 0.99 & 0.97 & 0.96 \\
$00^{\circ} \mathrm{N}$ & 1 & 1 & 1 & 1 & 1 & 1 & 1 & 1 & 1 & 1 & 1 & 1 \\
$10^{\circ} \mathrm{S}$ & 1.05 & 1.04 & 1.02 & 0.99 & 0.97 & 0.96 & 0.97 & 0.98 & 1 & 1.03 & 1.05 & 1.06 \\
$20^{\circ} \mathrm{S}$ & 1.1 & 1.07 & 1.02 & 0.98 & 0.93 & 0.91 & 0.92 & 0.96 & 1 & 1.05 & 1.09 & 1.11 \\
$30^{\circ} \mathrm{S}$ & 1.16 & 1.11 & 1.03 & 0.94 & 0.89 & 0.85 & 0.87 & 0.93 & 1 & 1.07 & 1.14 & 1.17 \\
$40^{\circ} \mathrm{S}$ & 1.23 & 1.15 & 1.04 & 0.93 & 0.83 & 0.78 & 0.8 & 0.98 & 0.99 & 1.1 & 1.2 & 1.25 \\
$50^{\circ} \mathrm{S}$ & 1.33 & 1.19 & 1.05 & 0.98 & 0.75 & 0.68 & 0.7 & 0.82 & 0.97 & 1.13 & 1.27 & 1.36
\end{tabular}

It seems that evaporation values were calculated by the Thornthwaite method (Table 4). the highest value was $421.95 \mathrm{~mm}$ in July, while its value was 2.09 in January. The low latent evaporationtranspiration period is limited (November, December, January, February, March) as the latent evaporation-transpiration value is less than $20 \mathrm{~mm}$, while the transitional period is represented by April, October, Values range between 40-100 mm, while the months from June to August represent the period in which the values of evaporation-transpiration are high between 100-400 mm.

\subsection{Water Surplus Period}

This period is characterized by the fact that the rates of rain in it exceed the rates of evaporation type latent (Hassan and Al-Ansari, 1976) and from this relationship, the true transpiration can be calculated as follows:

$$
\begin{gathered}
W S=P-P E \ldots \ldots \ldots P>P E \\
A E=P E
\end{gathered}
$$

Ws $=$ Water Surplus $(\mathrm{mm})$

$\mathrm{P}=$ Rain $(\mathrm{mm})$

$\mathrm{PE}=$ Evaporation - latent transpiration

$\mathrm{AE}=$ Evaporation - true transpiration

Water surplus means that rainfall values increase the values of corrected evapotranspiration through the given months of the year (WS = P > PET) (Jirjees et al., 2020). And the months represent December, January the months of water increase, which is the wet period, and the water increase in them reached between $2.2 \%$ to $10.55 \%$ from the annual rainfall schedule (2-3) and the transitional period represents the months of March to October.

$$
\begin{aligned}
& W S \%=\frac{W S}{P} * 100 \\
& W S \%=\frac{12.75}{98.611} * 100=12.92 \%
\end{aligned}
$$




\subsection{Water Deficit Period}

When rain is less than latent transpiration evaporation, rain equals evaporation - true transpiration $P<P E$

$W S=0$

$$
\begin{gathered}
W D=P E-P \quad \ldots \ldots \ldots P P E \\
A E=P
\end{gathered}
$$

Here, the water increase will be equal to zero

$\mathrm{WS}=0$

The months from February to November represent the period of water shortage and the months of February, March, April, May, June, July, August, September, October, and November represent the period in which the rain is the least possible or non-existent, meaning that the true evaporation transpiration $=0$ or as little as possible.

\subsection{Climatic Classification}

Based on Brown \& Cochem (1973), the humidity factor can be used to classify the climate according to the following equation:

$\mathrm{P}=$ Monthly average of rain

$$
H I=\frac{P}{P E}
$$

$\mathrm{PE}=$ Evaporation - monthly transpiration

The climate can be divided according to the following table

Regarding the application of the data in Table 8., it is attributed that the climate of the study area is according to what is shown in Table7. Very dry from May to October, dry in April, dewy in Mar and November, wet in months (December Feb. Jan).

Table 7. Climate assessment according to HI values (Brown \& Cochem, 1973)

\begin{tabular}{cc}
\hline Climate Condition & HI \\
\hline Wet & HI $>1$ \\
Dewy & $0.5<\mathrm{HI} \leq 1$ \\
Between wet and dry & $0.25<\mathrm{HI} \leq 0.5$ \\
Dry & $0.1<\mathrm{HI} \leq 0.25$ \\
very dry & $\mathrm{HI} \leq 0.1$ \\
\hline
\end{tabular}

Table 8. The climate classification for the study area according to the monthly humidity factor (HI) values

\begin{tabular}{lllllllllllll}
\hline & Jan. & Feb. & Mar. & Apr. & May. & Jun. & Jul. & Aug. & Sep. & Oct. & Nov. & Dec. \\
\hline HI & 5.24 & 1.52 & 0.61 & 0.1 & 0.03 & 0.0 & 0.0 & 0.0 & 0.0 & 0.05 & 0.68 & 2.67 \\
\hline
\end{tabular}

\section{Conclusions}

Climate, in general, is the sharp difference in temperature between night and day, summer and winter. Differences in climate were found in the study area. The study of climatic factors showed that the climate in the study area for the period between 2010-2020, where the monthly rates of temperature in the region ranged from 10.9 to 34.9 with a rate of 23.4 relative humidity, ranged from $14.75 \%$ to $57.26 \%$, at a rate of $33.4 \%$. As for evaporation - The annual latent yield was measured according to the Thornthwaite method, and it reached a total of $2016.11 \mathrm{~mm}$. Meteorological station's highest value was 
obtained in July (421.9), and the lowest value in January (3.66). Humidity coefficient (HD) It was found that the climate of the study area is dry to very dry "in all the months of the age except for the months (December, January, February) in which the climate is damp and the climate is dewy for March and between the dew and the elves for November.

\section{Acknowledgements}

The author expresses thanks and gratitude to the family, friends and all those who helped in this research, as well as special thanks and gratitude to Dr. Jawad Kazem Al-Mani'a for his assistance to perform the research as well as to my department and all the staff of the geochemistry laboratory at the University of Babylon. The authors are very grateful to the Editor in Chief Prof. Dr. Salih M. Awadh, the Secretary of Journal Mr. Samir R. Hijab. and the Technical Editors for their great efforts and valuable comments.

\section{References}

Al-Lhaebi, S. F., Al-Badrani, O. A., Al-Juboury, A. I., Mahanipour, A., 2020. Paleoclimatic insights On The Cenomanian-Turonian oceanic anoxic event (Oae2) From Northern Iraq based on calcareous nannofossils and geochemical data. Iraqi Geological Journal 53 (2C), 68-86.

Al- Taweel, B. H., 1983. Soil Genesis in Relationship to Ground Water Regimes in Hummocky Ground Water Movalne Area Near Hamlota Manitoba. Ph.D. Thesis University of Manitoba, Department of Soil Science, Manitoba, $220 \mathrm{P}$.

Hussain, A. M., Ibrahim, M. K., Abbas, H. N., 2000. Water Sciences at Dar Al Kutub Directorate for Printing and Publishing, Baghdad, 2000.

Al-Sudani, H. I., 2019. Temperature-Potential Evapotranspiration Relationship in Iraq Using Thornthwaite Method. Journal of University of Babylon for Engineering Sciences

Brown, L. H. and Cocheme, J., 1974. Study of the agrometeology of the high land of eastern Africa, WMO, Tech Note, 125: 197.

Hassan, H. A., and Al-Ansari, N. A., 1976. Surface runoff and ground water evaporation on Khnzir River catchment Iraq. Firest Arab Congress of Hydrology, Sirrya, 11p.

Manii, J. K., 2003. Hydrochemistry of the ground water and its relationship with the mineral of open aquifer sediment in selected location within Babylon Governorate, unpublished M.Sc Thesis University of Baghdad ,189p.

Mazor, M., 1990. Applied Chemical and Isotopic Ground Water Hydrology, New York, 274 p.

Shaker, S. N., 1985. Geomorphology of the sand dunes of the area confined between Al Kut - Diwaniyah Al Nasiriyah, unpublished M. Sc thesis, University of Baghdad, College of Science, $208 \mathrm{p}$.

Jirjees, S. J. Seeyan, S., and Kaiwan, K. F., 2020. Climatic Analysis for Pirmam Area, Kurdistan Region, Iraq. Iraqi Geological Journal 53 (1E), 75-92.

Thornthwaite, C.W., 1948. An approach towards a rational classification of climatic, Geographical Review, 38, 55-94. 